\title{
On the Innovative Application of China's Traditional Arts and Crafts in the Industry of Fashion Arts
}

\author{
Jin Lan \\ Shanghai Art \& Design Academy
}

\begin{abstract}
The language concerning traditional arts and crafts is increasingly applied in modern fashion designing, which has become the important design ideas by focusing on the traditions. By elaborating the recognition of traditional arts and crafts, its diversified emerges in fashion arts including its classification $\mathrm{s}$, materials, production methods, design methods and the diversity of design themes, the author discusses the creative application by combining the traditional arts and crafts and the modern fashion design and artistry. By explaining the traditional culture and analyzing its applications, the author explores the innovative application of traditional arts and crafts in the industry of modern fashion arts. The terminal aim is to link up the traditions and fashion, protect and inherit China's traditional arts and crafts, promote modern fashion brands and extend the cultural connotation of fashion brands.
\end{abstract}

\section{Introduction}

With the rapid development of China's economy, the industry of fashion arts has become the key loop in the China's industry chains. Here we have two hot issues. The first one is how to closely combine traditional arts and crafts with modern designing to fulfill their advantages with their development and promotion; The second one is how to rationally use China's traditional arts and crafts in various fashion designing to be "culture endorsement" of China's traditional culture in the fashion industry. Aiming at the above two problems, the author will elaborate in the following three aspects: One, China's traditional arts and crafts is the carrier of cultural innovation in the industry of modern arts; Two, the diversified emergence is the application of China's traditional arts and crafts in modern fashion arts; Three, China's traditional arts and crafts can and be able to actively promote the brand consciousness in modern fashion.

\section{China's traditional arts and crafts is the carrier of cultural innovation in the industry of modern fashion}

The industry of fashion arts has become the industry with potentials at home and abroad. The fashion arts must have its own cultural connotations, while cultural creativity is helpful in forming the unique designing styles, which can inspire the innovative thought and make it more competitive. If the modern fashion arts in one country wants to survive and develop in the global competition, it needs to focus on the design creativity and innovate them in the process of inheriting China's arts and crafts. Moreover, it needs to derive and dig the cultural connotation from the traditional culture in the country. The people's identity is shaped by sharing the history and forming its relative significance. Thus the designing philosophy with its national characteristics is formed 1 .

The cultural consumption begins to emerge in both the materials and spirits. The traditional arts and crafts in fashion arts is playing an important role in the development of one country. As the core strategy, the fashion art is always being popularized and promoted in economically developed countries or regions. The traditional arts and crafts in North Europe emphasizes the concept of simplicity. In early 19th century, the Nordics put forward that, no matter what the design was, it must meet the two requirements in the first place: practical and suitable. Therefore, the practicality and suitability is the unique design style in the fashion arts of North Europe. The designing concept of the fashion arts in Germany is its preciseness and rationality, which results in more high-class products by integrating its traditional arts and crafts and is the symbol of German Designing. From Victorian Style to Naturalistic Style advocated by the movement of arts and crafts, the arts and crafts of Great Britain influenced and is influencing the Europe Continent and even the United States of America. Up to now, these cultural and designing concepts are still influencing the fashion arts in these countries.

\footnotetext{
${ }^{1}$ the legacy café the holistic benefit of reviving lost arts, crafts and traditional skills through an early childhood intergenerational sustainable skills project[J].Diane Boyd.Education3-13.2020(2)
}

* Corresponding author: 1325@sada.edu.cn 
In China's designing and creative industry, the modern fashion arts is one of the most potential fields. The strategy must be established in order to research and develop, deconstruct and reconstruct the traditional arts and crafts and coordinate the development of modern fashion arts. The product design of our neighboring country, Japan, can be quickly integrated into the development trend of fashion industry, which is based on the research and inheritance of traditional crafts. In recent time, the proposal of enhancing cultural confidence has made China's fashion arts focus more on the traditional culture and connotation. By embedding China's traditional cultural elements, or using some traditional crafts and techniques which are identified as intangible cultural heritages has become a new design trend and is more and more accepted by the public. As the direct design concept and means, traditional arts and crafts covers many intangible spiritual culture, which are embodied in people's living habits, customs, values and aesthetics. Intangible cultural heritages such as grass weaving art, lacquer art and even embroidery art in traditional arts and crafts can be introduced into modern fashion art. On the one hand, fashion has more creativity. On the other hand, it is helpful to protect and promote the traditional arts and crafts. The combination of the industry of modern fashion design and China's traditional arts and crafts should be the demand of the development of the times, which is also the demand of Chinese people in the dual activities of aesthetics and consumption. It profoundly reflects the aesthetic and social significance of the forms of fashion art. Moreover, it extends and expands the main connotation of the fashion art innovation. Therefore, the innovative modern fashion art with abundant cultural connotation is formed.

\section{The diversified emergence is the application of China's traditional arts and crafts in modern fashion arts}

The traditional arts and crafts is the accumulation of culture, while fashion is the people's temporary worship of something in the society, which represents the latest trend in a certain time. In the field of fashion art, traditional arts and crafts can be integrated with the history, the material, the technology, the manufacturing, etc. The craft variety, the materials, the manufacturing techniques, the design techniques are quite different from each other.

\subsection{The diversity of process classifications}

In modern fashion art, the ceramic process has been more and more used in the home furnishing; the metalwork in the jewelry designing; the colored glaze in clothing decoration; the lacquer art in jewelry boxes; the cloisonné technique in vase decoration; the woolen embroidery in bag decoration, to name just a few. There are more process varieties are waiting for the designers to develop and utilize. The classifications of traditional arts and crafts are various, which can used in every aspect of fashion designing.

\subsection{The diversity of arts and crafts materials}

The materials used in the fashion designing includes the gold, the silver, the wood, the jade and the herbaceous plants in nature; the man-made or fired materials includes the glass, the ceramics, the cloths, the silk etc.; The applied materials includes both the soft materials and the hard materials with different textures. Sometimes, the use of unique materials represents the culture in a certain area because of its unique geology and climate, the mining and digging the materials are endowed with unique cultural characteristics. The application of materials should be based on the understanding the fundamental characteristics of the culture, which is in line with the modern design concept to reflect the instinct in selecting the materials in traditional culture in the long term. For example, in China's clothing industry, the traditional materials such as agate are used in designing necklaces and rings, which can endow the clothing with the new cultural connotation. In ancient time, the red agates symbolized love and hope. Even more, it is said that they can reduce stress and fatigue. Embroidery is increasingly used in the cultural and creative products. The embroidery is rich in diversities with different techniques, which is strongly expressed in modern fashion art.

\subsection{The diversity in the manufacturing}

Different crafts results in the different manufacturing methods in processing varieties, such as firing, engraving, weaving, freehand sketching, inlaying, molding etc, which can be applied in the fashion art. The fashion requires perfect presentation. Thus, the exquisite traditional arts and crafts needs to be integrated with the fashion designing. The exquisite techniques can give full play to the artistic appeal of design works, which is the unity of techniques and beauty in modern fashion designing. Techniques represented the advancement and productivity of the science and technology at that time. With the application of advanced design concepts and the hightech design means, the fashion industry is booming while the traditional culture is being protected and inherited.

\subsection{The diversity in designing methods}

The fundamental elements were derived in China's traditional costume culture. In which, the various design elements, such as the rotundity and square are the common patterns. Auspicious patterns have rich connotations. There are different patterns in different categories. Fashion design is done with the features of abundance and completeness, which express the richness, happiness and completeness in aesthetics. The traditional fundamental elements and patterns derived 
from traditions in the modern clothing and cultural and creative products are the expressions of traditional languages. The spiritual meaning of the concepts such as less is better than more and the simplicity in fashion designing is expressed in new ways by the natural, simple and frugal artistic conceptions. The designs in China focus on the planarization while those in the West focus on the three-dimensional objects. In traditional culture, the designs are usually symbolic and meaningful, which is quite different from the realism in the West. Therefore, the fashion industry in China has its own features because of these differences.

\subsection{The diversity in designing themes}

The innovative themes give fashion more languages. For example, the series pens The Little Prince manufactured by Montblanc, are the high-quality products by digging the theme from the stories. The reason why the cultural and creative products in the Imperial Palace are best-seller is the creative themes. The fashion design products with China's traditional cultural characteristics will stand out and catch the eye of the public. With the support of powerful statistical technology of databases, the collected information has become the asset which is easy to extracted and used 2, which makes it possible to introduce China's traditional arts and crafts into the new designing themes. Its values can be reflected in fashion designing and take a seat in world economy, which is still an important part in global cultural economy3.

\section{China's traditional arts and crafts can and be able to actively promote the brand consciousness in modern fashion}

China's traditional arts and crafts has its profound cultural background with a history of thousands of years. Fashion has a long history. However, for a long time, there is no brand consciousness in China's traditional arts and crafts. More people believe that China's industry of arts and crafts is small-sized, most of them are individual workshops. The mode that apprentice are trained by masters lasted and is existing now. The development of traditional arts and crafts markets is hindered. But if the brand consciousness of fashion industry can be integrated into traditional arts, in return, the connotation of fashion can be promoted by the traditional arts and crafts, both of them can possibly be developed well. In Japan, for instance, the lacquer wares by its traditional arts and crafts are researched and developed in molding, technology and

\footnotetext{
${ }^{2}$ Lindy Ryan. The visual imperative: creating a visual culture of data discovery[M]. Morgan kaufmann.2016

3 Paris and fashion: reflection on the role of the Parisian fashion industry in the cultural economy[ $\mathrm{J}]$. Solange montagne villette irene hardill international journal of sociology and social policy 2010(9/10)
}

pattern designing, by which its lacquer wares are sold globally. The reason is clear, its products are integrated into modern fashion life and can meet the requirements of modern society.

In France, in order to protect traditional arts and crafts, the organization of precious masters is established, the master list is compiled, the heritage history and works by the masters are exhibited. The most important is that their traditional arts and crafts are directly used in the field of modern designing and different design fields. From which, more modern products are actively developed, such as the handiworks using enamel craft have become one of most luxury brands. More examples are suitcases and bags manually weaved by straws and the costumes by using the technology of handmade laces.

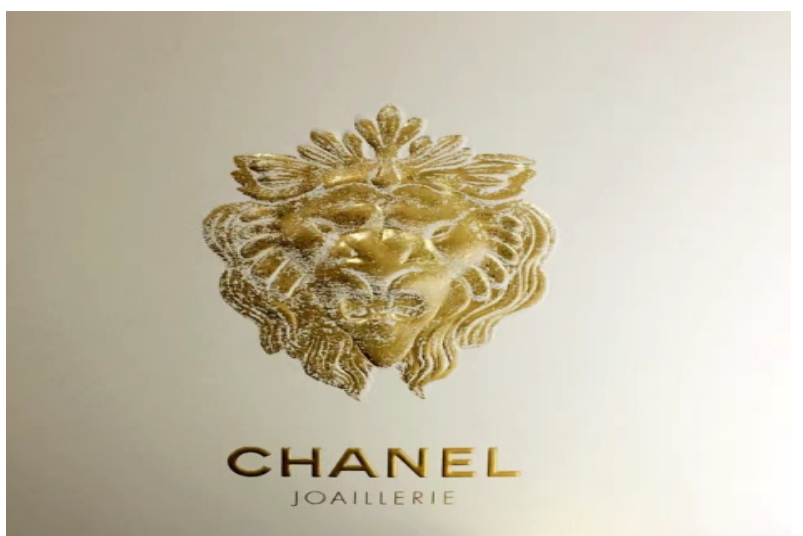

Figure1. French brand Chanel's packaging and printing process

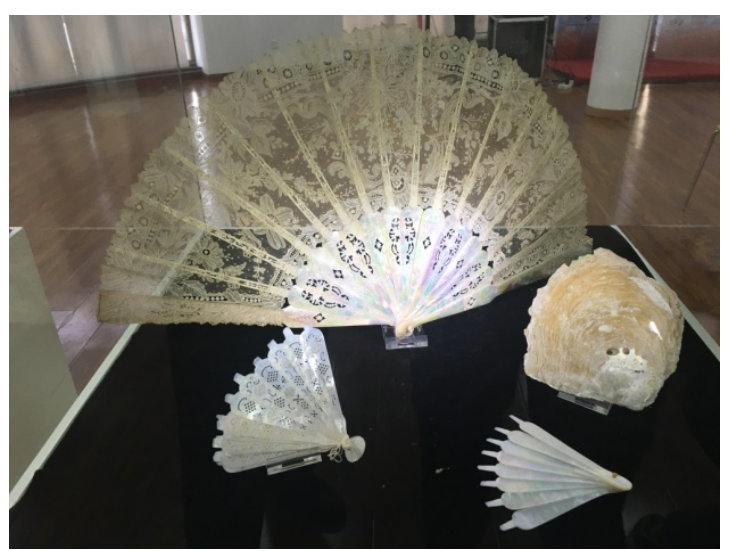

Figure 2. French hand-made decorative folding fans 
Germany is also the origin area of ancient culture in Europe, itself has a very unique source of artistic development. In Coburg, more products are developed

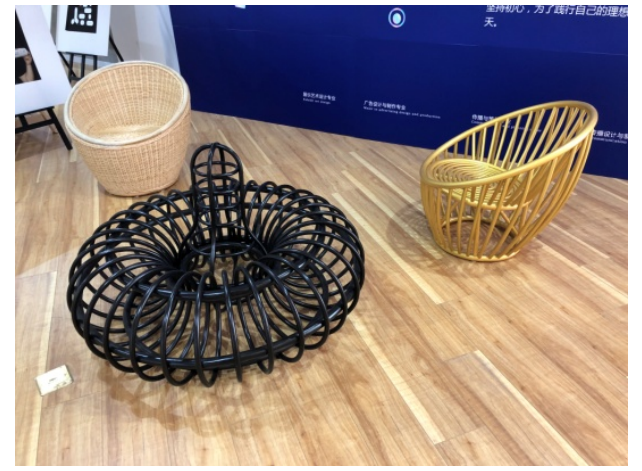

Figure 3. Modern wicker chair design

The designers in China begin to emphasize the cultural heritage in designing step by step. The traditional concepts are combined more with the modern elements. More fashion products with rich and profound cultural connotations are designed by Chinese designers. The design of modern fashion in China needs to protect and inherit China's unique national characteristics. Because traditions have their tenacious vitality and won't disappear in the impact of modern high-tech industry. The application of 3-D printing technology and Computer Numerical Control only benefit the traditional technology and process. It won't impact but start another design integrated with modern designing, which will endow China's fashion design with distinctive features and unique artistic temperament.

With the time flying, the lasting features have become one kind of recognizable cultural icons. The application of traditional arts and crafts in modern fashion art needs to establish the brand consciousness, more globalized Chinese brands enlightened by China's

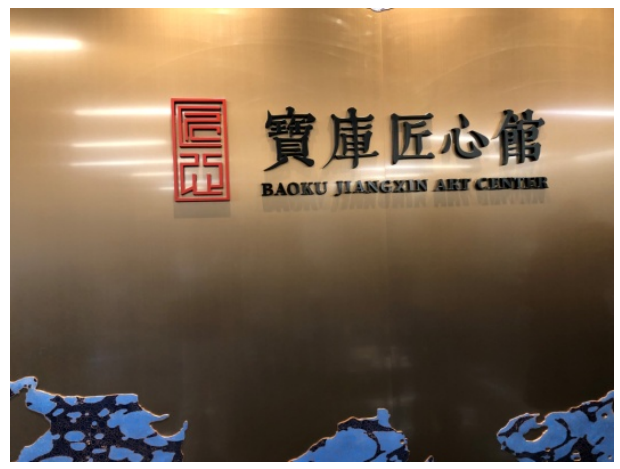

Figure 5. Baoku Jiangxin Art Center

Baoku Jiangxin Art Center, which is located in Shanghai Tower, devotes itself to protecting and inheriting China's traditional arts and crafts. Its exhibits of traditional arts and crafts range from decoration design, home design, weaving arts to jewelry design and so on. Almost every traditional process has its own by its rattan weaving process, such as the rattan chairs, the rattan tables, which have become the modern home fashion furniture (See Figure 3.).

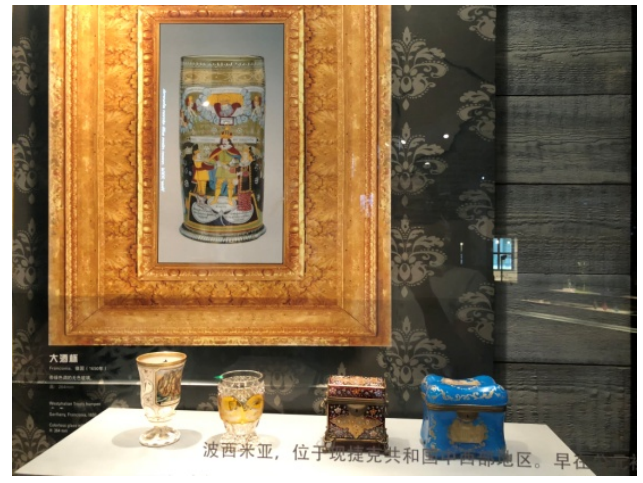

Figure 4. Czech glass products on display in the Glass Museum

traditional arts and crafts needs to be founded. Together with fashion art, to found the sustainable growth of cultural economy is the correct thought at present. The humanity attainment is improved while developing the economy. Excellent traditional culture can be compared to a kind of nutrition of fashion industry. The values should be diverse and abundant. To carry forward the traditional arts and crafts, we should protect them and innovate them at the same time. Starting from the brand consciousness, the carrier of traditional arts and crafts can make the products more vital for a long time. Only by developing the products with cultural artistry, from traditional materials and by traditional handcrafts can the international and influential Chinese brands be established. It is impossible to reinforce the promotion of Chinese brands, to inherit the culture and innovate the designing in a short time. We need more time to incubate, breed, adjust and improve before prestigious Chinese brands are established.

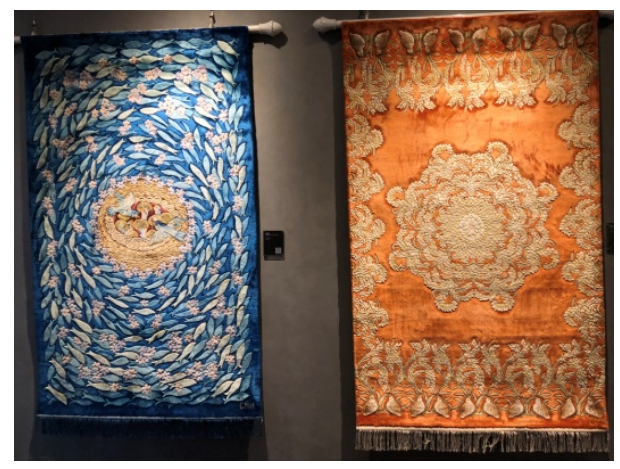

Figure 6. Tapestry craftsmanship exhibited in Baoku Jiangxin Art Center

brand. For example, the rosewood art brand of Yinzun Pavilion; the woodblock printing of Zhuxian Town; the enamel brand of Trends, are all the famous Chinese brands. This is a good phenomenon, in the past, some arts and crafts disappeared because of the lack of brands. Globally, we can find the exquisite enamel 
wristwatches brought by the Swiss Brand Patek Philippe and created by the enamel master Ms. Anita; And more, the neoteric enamel jewelry designed by the Italy Brand Bvlgari. The traditional enamel technique didn't disappear but became the mainstream craft in luxury brands. Of course, the common fashion brand products are updated frequently. Thus, how to rapidly integrate the traditional arts and crafts and apply them in the fashion products and quickly appear in the markets at home and abroad, which needs us to think about.4

The traditions are integrated with the fashion designing. After that, the concept of cyclic economy and sustainable design needs to be imbedded. The sustainable design includes not only the sustainability of resources but also the sustainability of social culture 5, and more, the innovation is only way to develop. The ideas in China's traditional aesthetics are influencing the modern fashion design ideas, the sustainable, recyclable concepts in traditional arts and crafts are innovatively integrated into modern elements 6, which urges the continuous renewal of innovation consciousness. Thus, the establishment of brands supplies the opportunity to build up China's national consciousness. The application of China's traditional cultural craft design is diversified in the ancient life. The traditional arts and crafts needs to be integrated into the works of modern fashion crafts. Inspired by this, the designed fashion arts will have their historical imprint and be a good inheritance of traditional arts and crafts.

\section{Conclusion}

The fashion design in China is comparatively weak at present, the designers need to know more about traditional culture and their humanity attainment needs to be improved in order to dredge the essence and spirit of China's traditional culture. The investigation, research, development and utilization of China's traditional handicrafts need to be strengthened. By understanding China's traditional culture and its features, the designers can understand the internal aesthetics of traditional arts and crafts and think about it in a creative way. By integrating designing ideas and manufacturing methods, the designers can construct the new modern fashion design concepts. The designers pay more attention to traditional arts and crafts and

${ }^{4}$ Fast fashion: response to changes in the fashion industry[J].Vertica Bhardwai Ann Fairhurst the international review of retail, distribution and consumer research 2010(1)

${ }^{5}$ Sustainable Design Futures: An open design vision for the circular economy in fashion and textiles[J]. Paul Smith, Jen Baille, Lynn-Sayers McHattie. The design journal. 2017(sup1)

${ }^{6}$ AMFI's Reality School: A circular economy agenda for fashion education[J]Nicholas Hall Fiona VelezColby. Art design \& communication in higher education 2018(1) even love traditional arts. With the help of advanced process engineering and diversified material development, the designers can actively construct the fashion design arts with China's cultural characteristics and propel the updating of fashion art industry. It is impossible for the above-mentioned innovation application research to cover all ranges. However, it is quite important to build traditional design consciousness and create the unique fashion art products in the international markets. The follow-up research and development is the innovative application of traditional arts and crafts. All in all, the present traditional arts and crafts is playing an important role in fashion designing. If so, more design and design brands will created and have a profound impact on the world.

\section{Acknowledgment}

This paper is the research result of 2019 Research and Innovation Project in Shanghai Art \& Design Academy.

Author brief: Jin Lan, female, graduated from Donghua University with Master of Engineering, the Associate Professor and the Senior Arts \& Crafts Artist, working as the Assistant Dean of WPP School of Visual Arts in Shanghai Art \& Design Academy, as the Deputy Secretary General of Special Committee of Graphic Vision in Teaching Guiding Committee of the Major of Art Design of Vocational Colleges in the Ministry of Education of the People's Republic of China.

\section{References}

1. The legacy café the holistic benefit of reviving lost arts, crafts and traditional skills through an early childhood intergenerational sustainable skills project[J].Diane Boyd.Education3-13.2020(2)

2. Lindy Ryan. The visual imperative: creating a visual culture of data discovery[M].Morgan kaufmann.2016

3. Paris and fashion: reflection on the role of the Parisian fashion industry in the cultural economy[J]. Solange montagne villette irene hardill international journal of sociology and social policy2010(9/10)

4. Fast fashion: response to changes in the fashion industry $[\mathrm{J}]$.Vertica Bhardwai Ann Fairhurst the international review of retail, distribution and consumer research 2010(1)

5. Sustainable Design Futures: An open design vision for the circular economy in fashion and textiles[J]. Paul Smith, Jen Baille, Lynn-Sayers McHattie. The design journal. 2017(sup1)

6. AMFI's Reality School: A circular economy agenda for fashion education [J] Nicholas Hall Fiona Velez-Colby. Art design \& communication in higher education 2018(1) 
7. Ludden, G.D., P. Hekkert. and H. N. Schifferstein. Surprise \& emotion. in proceedings of the 5th conference on design and emotion society. Gothenburg, Sweden: Chalmers University of technology. 2006

8. Condition analysis and forecasting in the fashion industry Mariusz Czekala; Agnieszka Bukietynska; Marek Gurak International Journal of Economics, Finance and Management Sciences. 2019

9. Green product development under competition: A study of the fashion apparel industry. Shu Guo; Tsan-Ming Choi; Bin Shen. European Journal of Operational Research. 2020

10. Agreement by design: The effect of visual harmony on responses to surveys Ulrich R. Orth. Journal of consumer behaviour. 2020 